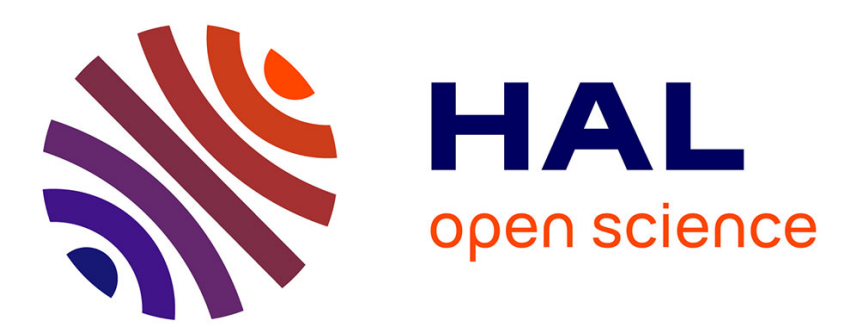

\title{
Analysis of Unbalanced Magnetic Pull in a multi-physic model of induction machine with an eccentric rotor
}

\author{
Xiaowen Li, A. Bourdon, D. Remond, S Koechlin, D Prieto
}

\section{To cite this version:}

Xiaowen Li, A. Bourdon, D. Remond, S Koechlin, D Prieto. Analysis of Unbalanced Magnetic Pull in a multi-physic model of induction machine with an eccentric rotor. 2nd World Congress on Condition Monitoring, Dec 2019, Singapore, Singapore. 10.3850/978-981-11-0744-3 . hal-02977541

\section{HAL Id: hal-02977541 \\ https://hal.science/hal-02977541}

Submitted on 28 Oct 2020

HAL is a multi-disciplinary open access archive for the deposit and dissemination of scientific research documents, whether they are published or not. The documents may come from teaching and research institutions in France or abroad, or from public or private research centers.
L'archive ouverte pluridisciplinaire HAL, est destinée au dépôt et à la diffusion de documents scientifiques de niveau recherche, publiés ou non, émanant des établissements d'enseignement et de recherche français ou étrangers, des laboratoires publics ou privés. 


\title{
Analysis of Unbalanced Magnetic Pull in a multi-physic model of induction machine with an eccentric rotor
}

\author{
$2^{\text {nd }}$ World Congress on Condition Monitoring (Singapore 2-5 December 2019)

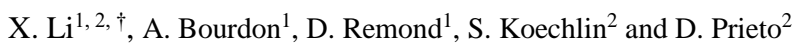 \\ ${ }^{\dagger}$ Univ Lyon, INSA-Lyon, CNRS UMR5259, LaMCoS, F-69621, Villeurbanne, France. \\ ${ }^{\dagger}$ E-mail : xiaowen.li@insa-lyon.fr \\ ${ }^{1}$ Univ Lyon, INSA-Lyon, CNRS UMR5259, LaMCoS, F-69621, Villeurbanne, France. \\ ${ }^{2}$ NIDEC PSA emotors, 212, Bd Pelletier - 78955 Carrieres-Sous-Poissy.
}

\begin{abstract}
Based on a multi-physic model of an asynchronous electrical machine with a strong electro-magnetomechanical interaction, the Unbalanced Magnetic Pull (UMP) generated from the uneven air-gap due to the rotor eccentricity is calculated and discussed. The proposed model includes strong couplings between mechanical, magnetical and electrical behaviors, particularly the relationship between angle sampling and time sampling about the rotor position which introduces the Instantaneous Angular Speed. Simulations with different input static eccentricity values are investigated in rated operation and the effects of UMP on the dynamic behavior of the whole system are analysed. Vibration analysis is performed at the supports to extract information in vibration signals for eccentricity monitoring.
\end{abstract}

Keywords: Unbalanced Magnetic Pull (UMP), asynchronous electrical machine, eccentric rotor, rotor center orbit, multi-physic model

\section{Introduction}

Unbalanced Magnetic Pull (UMP) is a radial electromagnetic force generated in the uneven airgap of the electrical machine when a rotor eccentricity exists. Usually it is ignored in the vibration analysis due to the difficulty of its measurement. However, once it is produced, it will pull the rotor toward the direction of the minimum airgap and continues to worse the eccentric situation. Noise and vibration are generated inside of motors which increase the bearing wear and other NVH problems on the external structure. In the industry, sometimes the motor needs to be installed on a poorly stable structure like a cantilever or a long flexible shaft. Under the effect of gravity, the buckling of the shaft increases the rotor eccentric level and potentially leads to the rotor-stator contact during the operation that may destroy windings or motor inside structure. Considering that an electrical machine is a multi-physic system consisting of three different fields that operate together and interact each other, a multi-physic analysed model is established to study the effects of UMP on the vibration behaviour of the induction machine with an eccentric rotor. A particular attention is paid to the rotor angle position which is 
considered as an output without any assumption on it's time history. This relationship offers the capability to describe precisely the cyclic phenomena (component with discrete geometry in rotation) and time phenomena (as the resonance in mechanical parts).

In this paper, the simulation results about $10 \%$ eccentricity of the average airgap distance are discussed firstly to present the effect of UMP to the whole system. Afterwards several simulation results about different eccentricity values are compared to highlight the linear variation with small eccentricities and nonlinear variation effect appearing for large eccentricity values. The rotor center orbit is studied to analyse the stability of the system. The connection between the support vibration and UMP is also analysed at the end of the paper to explain one of the important vibration sources in the electrical machines and how to extract information in vibration signals for eccentricity monitoring.

\section{Method of analysis}

\subsection{Multi-physic model}

Fourati et al. have proposed a multi-physic model about a 3-phases induction machine based on angular approach in [1]. In the present paper, this electro-magneto-mechanical interaction is reinforced by adding the coupling of the UMP $\left(F_{e m x}, F_{e m y}\right)$ generated inside of the motor due to the air-gap eccentricity. The modified strong multi-physics coupling is described in Figure 1.

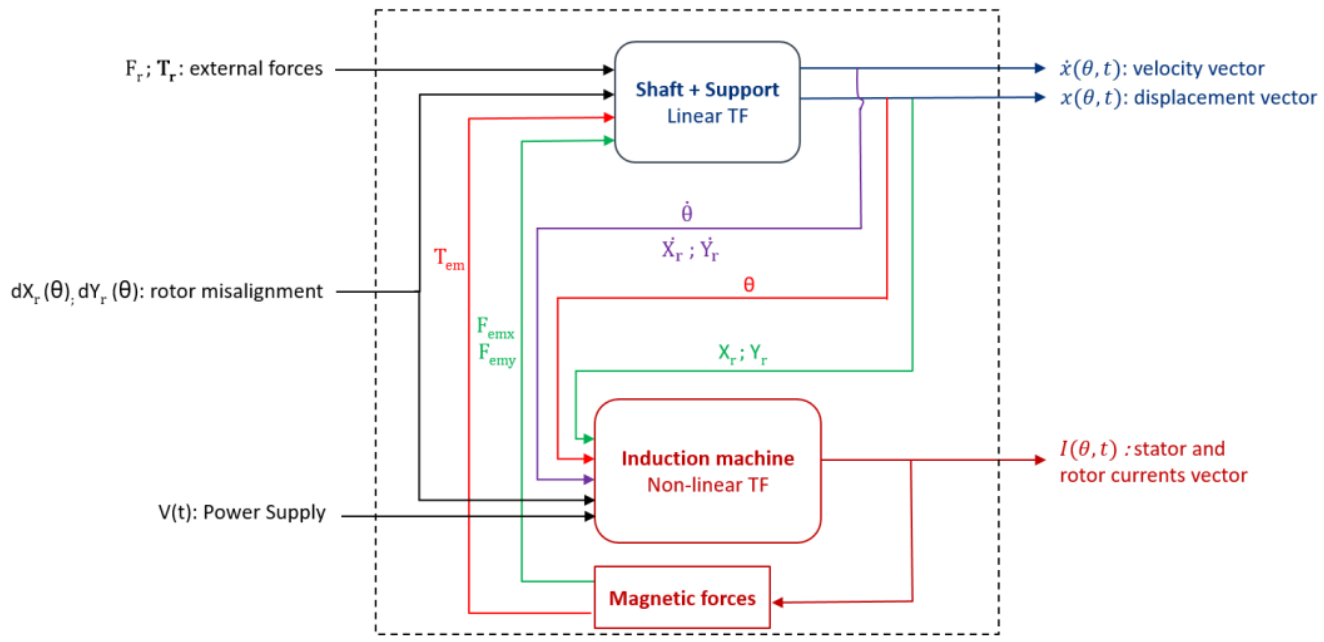

Figure 1: Multi-physics couplings.

\subsection{Effective air-gap distance}

Considering the rotor eccentricity, the air-gap distance around the periphery of the rotor is no longer uniform. In most literatures, people used to calculate it by an approximative expression as a function of the shaft rotation angle as in [2]. Only the rotor whirling motion is considered so the rotor center has no 
variation in terms of rotation angle. Hence in this paper, a formula of instantaneous effective air-gap distance as a function of rotor center coordinates is defined in (1) according to Figure 2.

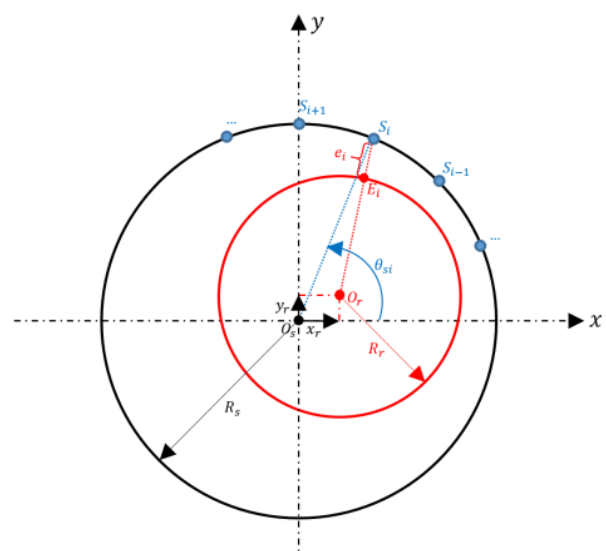

Figure 2: Calculation of instantaneous air-gap associated with the stator tooth i.

$$
e_{i}\left(x_{r}, y_{r}\right)=\sqrt{R_{s}^{2}-2 R_{s}\left(\cos \theta_{s i} \cdot x_{r}+\sin \theta_{s i} \cdot y_{r}\right)+x_{r}^{2}+y_{r}^{2}}-R_{r}
$$

where $R_{S}$ and $R_{r}$ are the radius of stator inner ring and rotor outer ring respectively, $\theta_{s i}$ is the anglar position of each stator tooth and $x_{r}$ and $y_{r}$ are the coordinate of the rotor center. This is the effective air-gap distance between each pair of stator and rotor teeth to be adapted with the Ostovic model from [9] used to calculate the air-gap permeance.

\subsection{Calculation of UMP}

Oppositively from the Maxwell stress tenseur method used in the references [2, 3, 4, 6, 8], in our model UMP is achieved by the principle of virtual work $[1,5,7]$ to obtain a more realistic UMP value in a simpler manner. Therefore, each component of UMP is calculated by deriving the magnetic co-energy along the $\mathrm{x}$ and $\mathrm{y}$ direction according to (2) and (3).

$$
\begin{aligned}
& F_{e m x}=\frac{1}{2} \sum_{i}^{n_{s}} \sum_{j}^{n_{r}} \emptyset_{i j}^{2} \cdot\left(-\frac{1}{p_{i j}^{2}}\right) \cdot \frac{\partial p_{i j}}{\partial x} \\
& F_{\text {emy }}=\frac{1}{2} \sum_{i}^{n_{s}} \sum_{j}^{n_{r}} \emptyset_{i j}^{2} \cdot\left(-\frac{1}{p_{i j}^{2}}\right) \cdot \frac{\partial p_{i j}}{\partial y}
\end{aligned}
$$

where $n_{s}$ and $n_{r}$ are the stator and rotor tooth number respectively, $\emptyset_{i j}$ is the magnetic flux transferred in permeance network of the air-gap area and $p_{i j}$ is the air-gap permeance between each pair of stator and rotor teeth.

\section{Results and discussions}

\subsection{Simulation results of the case with $10 \%$ Ee static eccentricity}


$10 \%$ static eccentricity of the average airgap distance is introduced in the horizontal axis (x axis) to perform a simulation in rated operation. In order to highlight the strong electro-magneto-mechnical interaction of this multi-physic model called as "Model EMM", a similar model known as "Model EM" without mechanical coupling is established with a fixed rotor center.

\subsubsection{Variation of UMP}
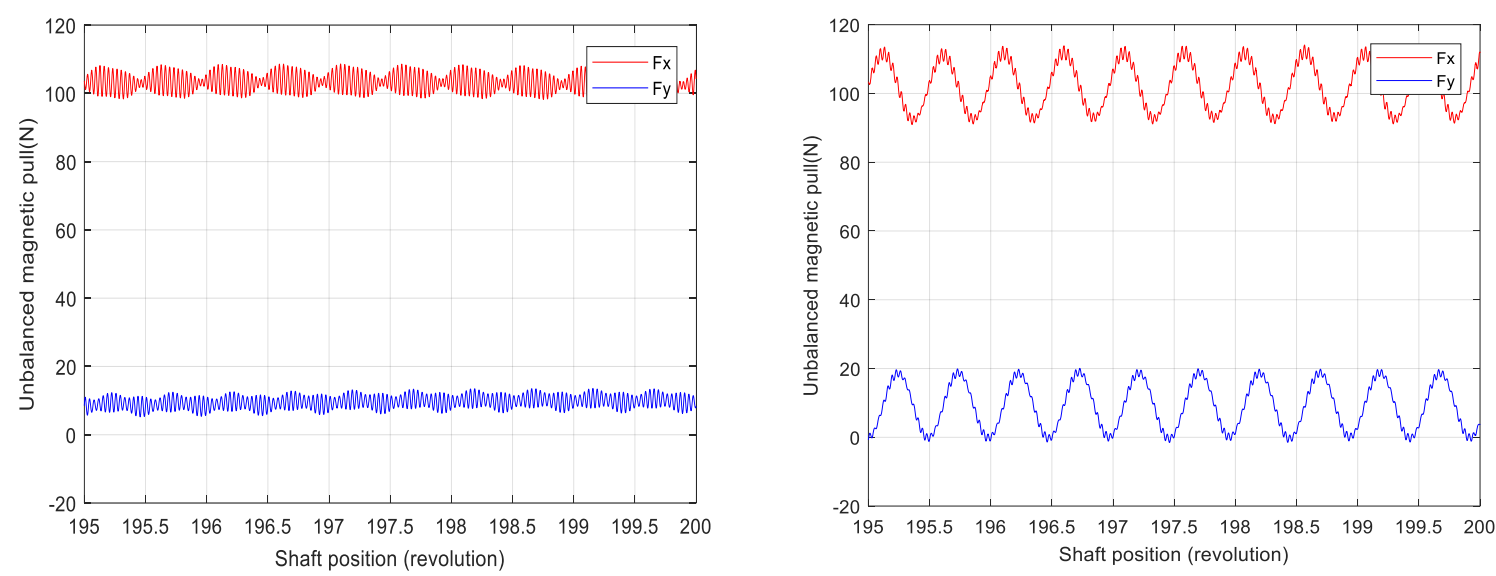

Figure 3: Variation of UMP as a function of shaft position (Left: Model EMM; Right: Model EM).

It can bee seen in Figure 3 that with an input static eccentricity, the two models generate 2 UMP components that fluctuate around two constant values. It's reasonable that the $\mathrm{x}$ component is bigger than y component because the eccentricity is set up in the $\mathrm{x}$ axis direction. However the average value of y component isn't zero which means the UMP resultant force doesn't point to the narrowest air-gap direction but rotates with a small angle from it. According to [10], this can be explained as the effects of the compensation currents induced in the rotor cage bar when facing the alternation of the big and small air gap. If two model results are compared, even their average values are almostly the same, those amplitudes from the model EM are bigger than those simulated from model EMM. It illustrates that without a mechanical coupling, UMP is overestimated.

\subsection{Variation of UMP with different eccentricities}

\subsubsection{With a relatively small eccentricity}

The polar diagram of UMP is realized by plotting the variation of Fy as a function of Fx in the polar coordinate. As shown in Figure 4, the arrows are plotted by the average values of (Fx, Fy) with the solid line while the trajectory at the end of each arrow represents their fluctuation in the last revolution with the dotted line. The magnitudes of UMP increase proportionally with the increase of the input static eccentricity while their offset angle hardly changes. The fluctuation in the case of $40 \% \mathrm{Ee}$ is bigger than others because of the strong modulation phenomena. 


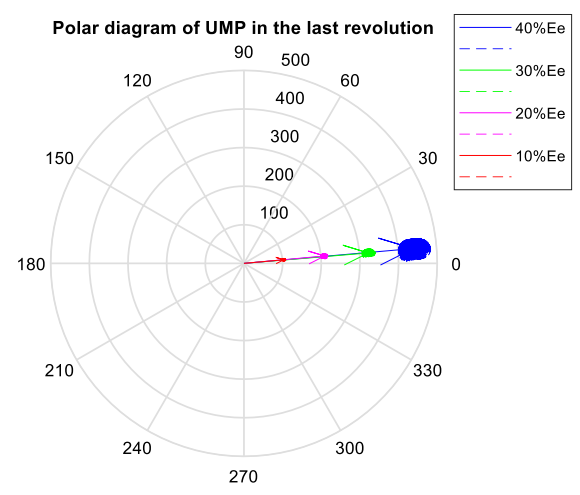

Figure 4: Polar diagram of UMP with different eccentricities in rated operation.

\subsubsection{With a relatively large eccentricity}

In rated operation, once the eccentricity exceeds $40 \% \mathrm{Ee}$, some nonlinear effects appear in all the simulation results. From Figure 5, different from the variation of UMP with $40 \%$ Ee, there is a strong pulsation emerged in the case with $50 \%$ Ee. The global magnitudes increase largely even the eccentricity amplifies only by 1.25 times. Meanwhile the variation of Fy component fluctuates almost at the same level as Fx component does. That's why in Figure 7, the rotor center orbit of $40 \% \mathrm{Ee}$ converges to a small circle close to the initial rotor center position while the rotor center orbit with $50 \%$ Ee rotates around the initial position with a relatively big radius. From the angular spectrum of UMP magnitude given in Figure 6, despite of the even harmonics of the supply frequency, some modulations between the harmonics of $f_{t}$ and those supply frequency harmonics will appear in the case of $50 \%$ Ee. It's not clear how to explain the origin of $f_{t}$ but it will increase with the increase of rotation speed. This strong modulation phenomenon also appears in other simulation results with $50 \%$ Ee, for example the variation of electromagnetic torque will fluctuate with a larger amplitude. This will potentially increase the risk of instability of the whole system.
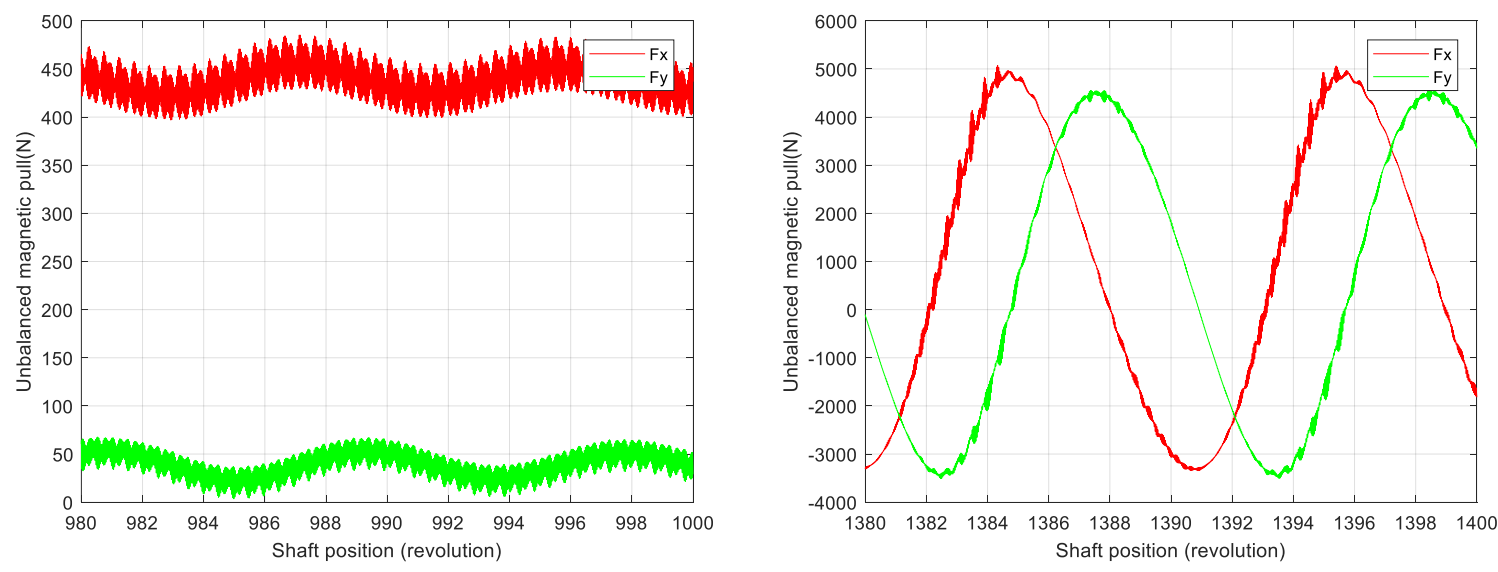

Figure 5: Variation of UMP as a function of shaft position (Left: $40 \%$ Ee; Right: $50 \%$ Ee). 

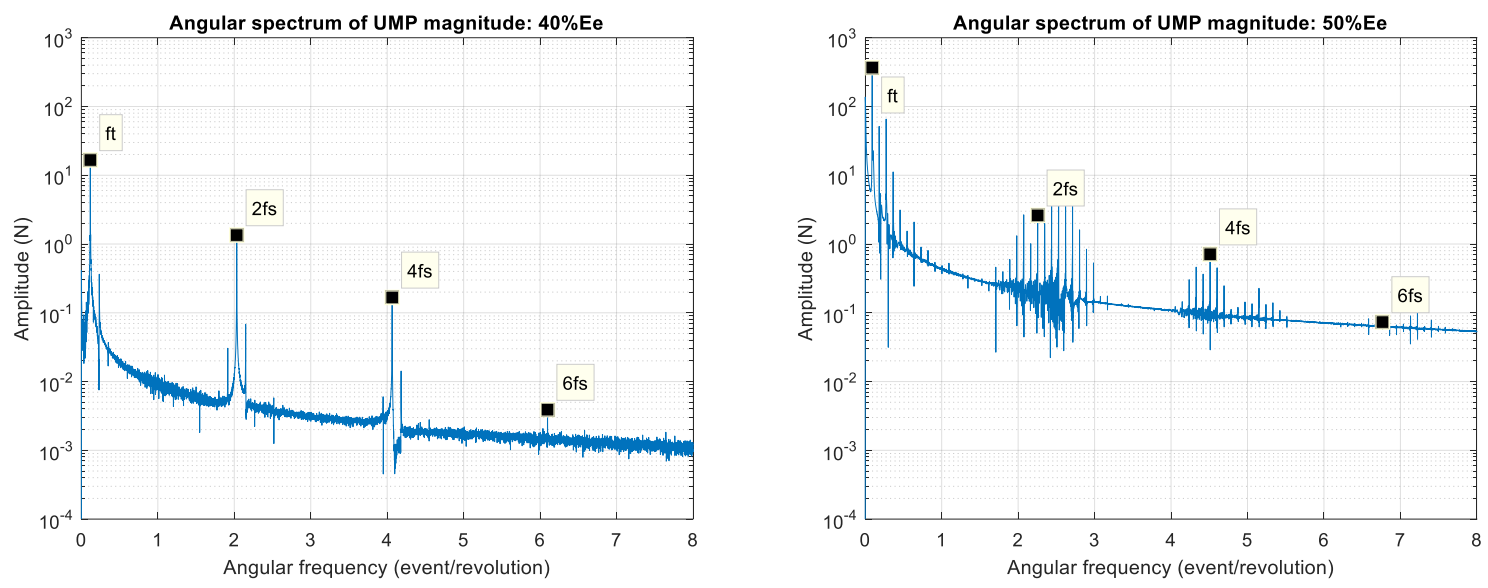

Figure 6: Angular spectrum of UMP magnitude.
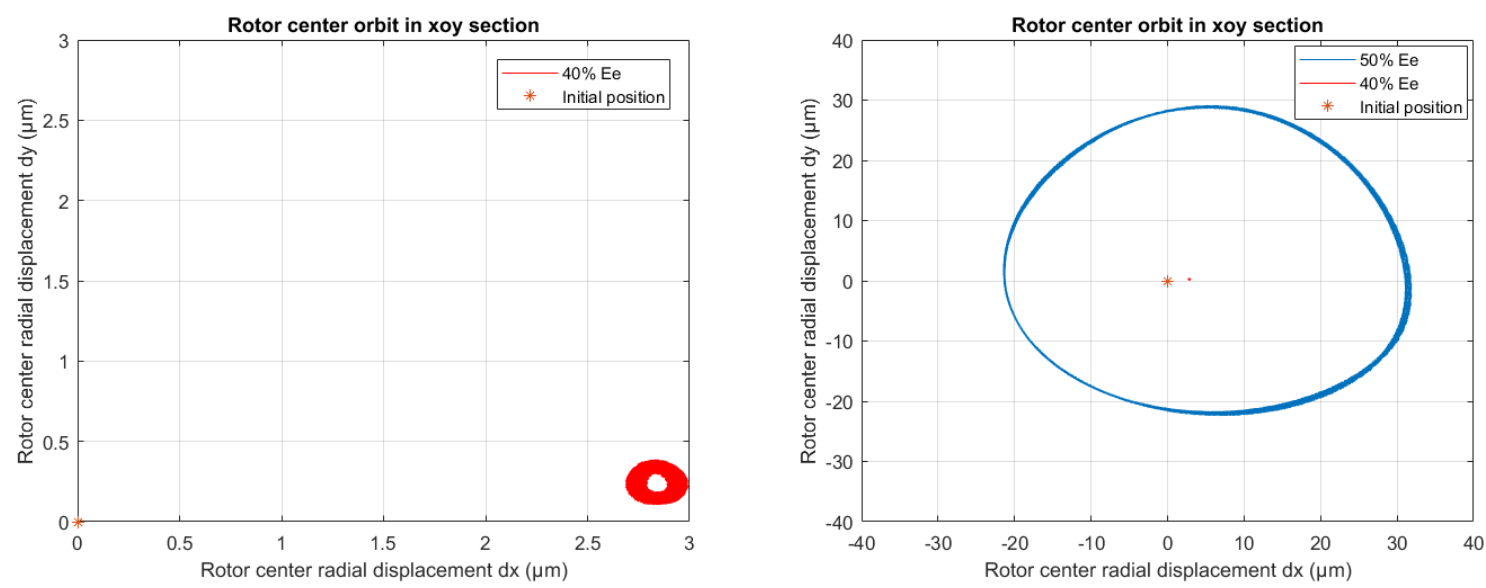

Figure 7: Rotor center orbit in xoy section.

\subsection{Vibration analysis from the support acceleration}

Based on the simulation with 10\%Ee input static eccentricity, the translation acceleration of support 1 from the mechanical part is analysed along two directions. In order to study their periodicity, their angular spectra are compared and presented in Figure 8. From three spectra, all the important characteristic frequencies can be identified including $2 f_{\theta s}=2.032 \mathrm{ev} / \mathrm{rev}, N_{r}=30 \mathrm{ev} / \mathrm{rev}$ and the modulation $N_{r} \pm 2 f_{\theta s}$ that are caused by the input eccentricity. However from the spectra of UMP and the acceleration along $\mathrm{x}$ axis "Accx 1 ", more frequencies like the harmonics of $6 f_{\theta s}=6.096 \mathrm{ev} / \mathrm{rev}$ allowed to be recognized although the spectrum of UMP is richer than that of Accx 1 considering that Accx1 is an indirect signal excited by the UMP. Furthermore, by comparing the amplitude of the frequency $30 \mathrm{ev} / \mathrm{rev}$ between the spectra of Accx1 and Accy1, it's simple to distinguish the static eccentricity appeared in which direction. 

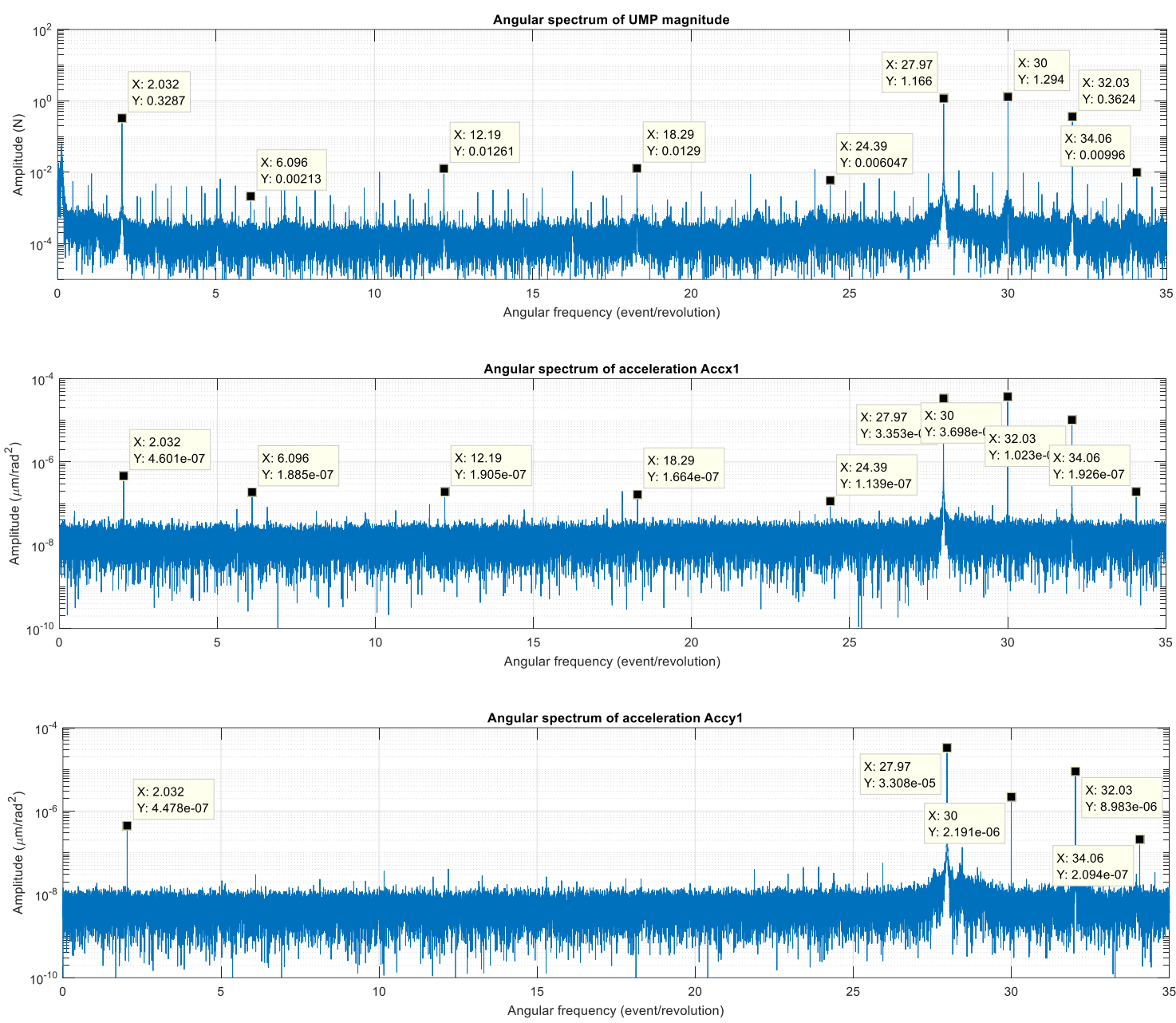

Figure 8: Angular spectrum of different results (Top: UMP magnitude, middle: translation acceleration of support 1 along $\mathrm{x}$; Bottom: translation acceleration of support 1 along $\mathrm{y})$

\section{Conclusions}

By adding the coupling of UMP with an unfixed rotor center, the multi-physic induction machine model based on angular approach is developed in the term of electro-magneto-mechnical interactions. The effective air-gap distance is defined as a function of the rotor center coordinate to calculate the UMP with different rotor eccentricities. The variation of UMP is more reasonable when compared with the results from the model without mechanical coupling. An offset angle of UMP resultant force is detected from the direction of the narrowest airgap which doesn't change with the variation of a relatively small eccentricity and meanwhile their UMP magnitude increases linearly with the augementation of the eccentricity. In the case of a relatively large eccentricity, nonlinear effects appear to all the simulation results and the harmonics begin to show up in their angular spectrum. The whole machine tends to be instable. The spectra of UMP and those of the translation acceleration from support 1 demonstrate the possibility of detecting the rotor eccentricity from the vibration analysis of support part. It should be 
noted that due to the tangential component of UMP in respect of narrowest air-gap direction, the vibrations can be detected from both the two directions.

\section{Acknowledgements}

Authors gratefully acknowledge the support of Association National Research Technology of France and Enterprise Nidec Leroy Somer.

\section{References}

[1] A. Fourati et al. Angular-based modeling of induction motors for monitoring. Journal of Sound and Vibration, 395:371-392, 2017.

[2] D. Guo, F. Chu, and D. Chen. The unbalanced magnetic pull and its effects on vibration in a three-phase generator with eccentric rotor. Journal of Sound and Vibration, 254(2):297-312, 2003.

[3] X. Han and A. Palazzolo. Unstable force analysis for induction motor eccentricity. Journal of Sound and Vibration, 370:230-258, 2016.

[4] T. P. Holopainen. Electromechanical interaction in rotordynamics of cage induction motors. Number 543 in VTT Publications. 2004, pp.543.

[5] A. Mahyob et al. Induction machine modelling using permeance network method for dynamic simulation of air-gap eccentricity. In 2007 European Conference on Power Electronics and Applications, EPE, 2007.

[6] X. Xu, Q. Han, and F. Chu. Nonlinear vibration of a generator rotor with unbalanced magnetic pull considering both dynamic and static eccentricities. Archive of Applied Mechanics, 86(8):1521-1536, 2016.

[7] F. Boy and H. Hetzler. A co-energy based approach to model the rotordynamics of electrical machines, volume 63 of Mechanisms and Machine Science. 2019.

[8] A. C. Smith and D. G. Dorrell. Calculation and measurement of unbalanced magnetic pull in cage induction motors with eccentric rotors. part 1 : Analytical model. IEE Proceedings: Electric Power Applications, 143(3) :193-201, 1996.

[9] V. Ostovic, Dynamics of Saturated Electric Machines, $1^{\text {st }}$ ed., New York USA, SpringerVerlag, 1989.

[10] J. Saint-Michel, Influence of rotor eccentricity on IR motor $C, 1^{\text {st }}$ ed., Nidec Leroy-Somer, France, 2001. 